\title{
PENERAPAN FORWARD CHAINING DALAM SISTEM PAKAR UNTUK MENDIAGNOSIS PENYAKIT PADA ANAK
}

\author{
Ahmad Fauzi \\ Program Studi Teknik Informatika \\ Universitas Buana Perjuangan Karawang \\ e-mail : afauzi@ubpkarawang.ac.id
}

\begin{abstract}
Abstrak
Anak merupakan harapan bagi orang tua. Kesehatan anak menjadi perhatian penting agar anak dapat tumbuh dan berkembang sesuai harapan. Keterbatasan pengetahuan orang tua dan biaya konsultasi kesehatan yang relatif mahal menimbulkan kebutuhan akses akan pengetahuan kepakaran tersebut. Sistem pakar untuk mendiagnosis penyakit pada anak dirancang menggunakan metode pengembangan sistem Expert System Development Life Cycle (ESDLC) dengan penerapan teknik penalaran inferensi forward chaining. Penalaran untuk menentukan kesimpulan dimulai dari gejala penyakit sebagai fakta. Gambaran inferensi dapat terlihat pada decission tree dari sistem yang dirancang. Sistem pakar telah menggunakan basis pengetahuan untuk menentukan penyakit.
\end{abstract}

Kata Kunci : Expert System, forward chaining, decission tree.

\section{PENDAHULUAN}

Anak merupakan generasi penerus yang didambakan oleh setiap orang tua. Pengasuhan yang terbaik dilakukan orang tua untuk menjamin kebahagiaan anak dan kehidupannya dimasa yang akan datang. Bagi Bangsa Indonesia, anak merupakan aset bangsa yang perlu diberikan pendidikan dan pengasuhan yang baik untuk peningkatan kualitas bangsa. Kesehatan anak menjadi sangat penting untuk dijaga baik oleh orang tua maupun pemerintah melalui program-program peningkatan kesehatan anak agar dapat tumbuh dan berkembang sesuai harapan.

Masa usia anak adalah rentan terhadap kuman penyakit karena pada masa anak adalah masa bermain yang belum mengerti bahaya dan dampak kesehatan. Perlu pengetahuan orang tua untuk memberikan penjelasan dan pengasuhan yang baik agar anak-anaknya sehat. Kemampuan orang tua untuk mengetahui gejala-gejala bahkan penyakit yang timbulkan relatif sangat sedikit. Kemampuan tersebut juga berasal dari turun temurun pengetahuan yang dimiliki oleh orang tuanya. Kehadiran petugas kesehatan sebagai ahli/pakar penyakit pada anak belum menumbuhkan kesadaran pada orang tua di daerah untuk mengetahui lebih banyak mengenai penyakit pada anak.

Sistem pakar (Expert System) adalah sistem yang berusaha untuk mengadopsi pengetahuan manusia ke komputer agar dapat menyelesaikan masalah seperti yang biasa dilakukan oleh pakar. Sistem pakar dapat mengumpulkan dan menyimpan pengetahuan seorang pakar menjadi basis pengetahuan sebagai sumber dalam menentukan nasehat yang diberikan.

Pemanfaatan sistem pakar untuk mendiagnosa penyakit pada anak telah dilakukan sebelumnya menggunakan Certainty Factor oleh Luther (2012), Helen dkk (2014). Aplikasi sistem pakar yang dibangun berbasis desktop menggunakan Microsoft Access dan Visual Basic 6.0 dan berbasis mobile android. Berdasarkan gejala yang diinputkan, aplikasi dapat menampilkan jenis penyakit dan nilai $\mathrm{CF}$ dari penentuan jenis penyakit yang disimpulkan sesuai dengan basis pengetahuan yang telah didefinisikan.

Penelitian saat ini adalah melakukan penerapan forward chaining untuk menghasilkan kesimpulan penentuan penyakit pada anak. Mengacu pada penelitian sebelumnya, penyakit yang dibahas adalah 7 jenis penyakit pada anak. Perbedaan dengan penelitian sebelumnya adalah penggunakan inferensi forward chaining dalam pengambilan kesimpulan serta rancangan sistem menggunakan permodelan objek. Hasil penelitian diharapkan dapat memberikan hasil nasehat sesuai dengan basis pengetahuan dan dengan urutan langkah sesuai dengan inferensi forward chaining.

\section{TINJAUAN PUSTAKA}

A. Sistem Pakar

Beberapa definisi sistem pakar sebagai berikut :

1) Sistem pakar adalah salah satu cabang kecerdasan buatan yang menggunakan pengetahuan-pengetahuan khusus yang dimiliki oleh seorang ahli untuk menyelesaikan suatu masalah tertentu (Giarratano dan Riley, 2005). 
2) Sistem pakar adalah program computer yang didesain untuk meniru kemampuan memecahkan masalah dari seorang pakar. Pakar adalah orang yang memiliki kemampuan atau mengerti dalam menghadapi suatu masalah. Lewat pengalaman, seorang pakar mengembangkan kemampuan yangmembuatnya dapat memecahkan permasalahan dengan hasil yang baik dan efisien (John Durkin, 1994)

\section{B. Forward Chaining}

Menurut Giarratano dan Riley (2002: 145) Forward chaining disebut penalaran bottom-up karena alasan dari bukti tingkat rendah, fakta, untuk kesimpulan tingkat tertinggi yang didasarkan pada fakta-fakta. Penalaran Bottom-up dalam sistem pakar analog dengan pemrograman konvensional bottom-up. Fakta adalah unit dasar dari paradigma berbasis pengetahuan karena mereka tidak bisa diurai ke dalam unit yang lebih kecil yang memiliki arti. Misalnya, fakta "bebek" memiliki arti yang pasti sebagai kata benda dan sebagai kata kerja. Namun, jika Apakah dipecah lebih jauh, hasilnya adalah huruf $\mathrm{b}, \mathrm{e}, \mathrm{b}$, e dan $\mathrm{k}$, yang tidak memiliki arti khusus. Dalam program konvensional unit dasar makna adalah data. Biasanya, konstruksi tingkat yang lebih tinggi yang terdiri dari tingkat yang rendah diletakkan di bagian atas. Berikut konsep dasar Forward Chaining.

Konsep perancangan mekanisme inferensi pada sistem pakar dengan metode inferensi, kesimpulan diambil berdasarkan data-data atau masukan-masukan yang telah diinputkan oleh pengguna melalui antarmuka aplikasi. Mekanisme inferensi forward chaining (David, 2014) digambarkan sebagai berikut:

1) Pengguna menjawab pertanyaan dengan menjawab "YA" atau "TIDAK" berdasarkan gejala dan penyakit. Pada tahap ini, sistem akan menyimpan data "YA" dalam temp sedangkan untuk jawaban "TIDAK" tidak akan disimpan. Data yang disimpan nantinya akan kumpulkan menjadi suatu kumpulan fakta dalam tabel rule (IF_Clause).

2) Pengguna mengklik tombol "Lihat Hasil Tes Diagnosa". Tahap ini adalah tahap sistem memproses fakta yang telah diperoleh dari gejala dan penyakit, kemudian mencocokkannya dengan daftar aturan (rule) yang telah dibuat untuk menghasilkan fakta baru berupa kesimpulan tes atau hasil tes.

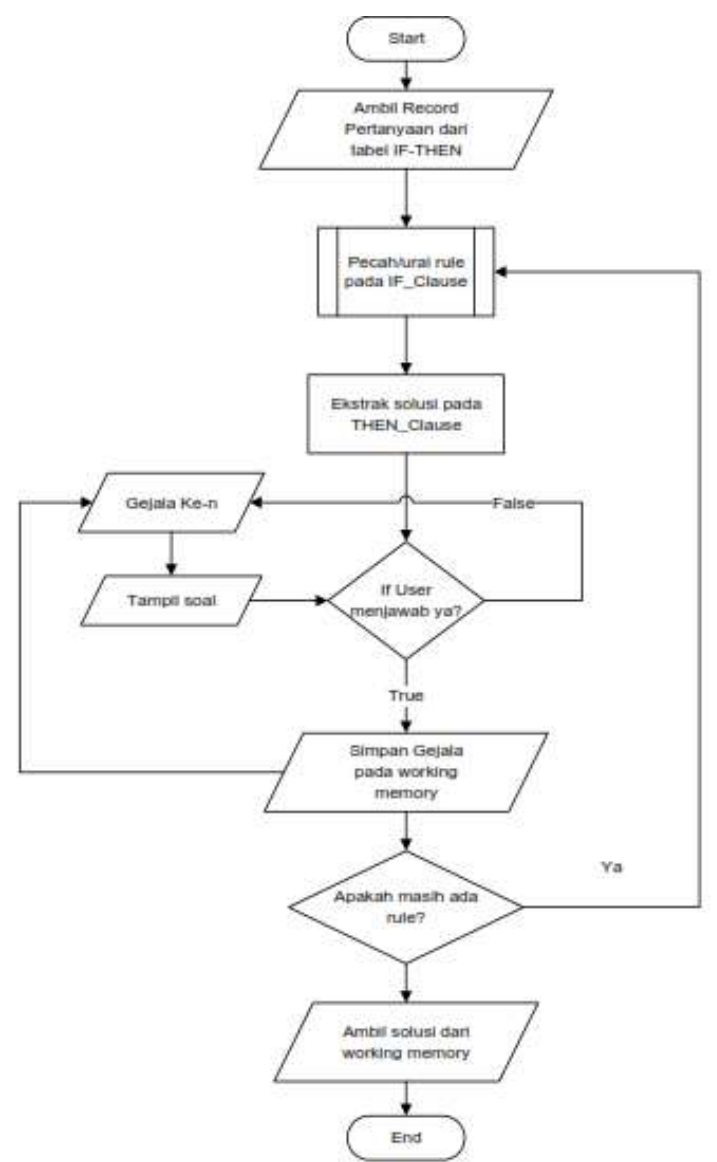

Gambar 1 : Mekanisme Inferensi Forward Chaining 


\section{METODE PENELITIAN}

Penelitian yang dilakukan menggunakan metode pengembangan Expert System Development Life Cycle (ESDLC). Metode ini berisi tahapan langkah pengembangan sistem pakar yang sesuai mulai dari penilaian, akuisisi pengetahuan, desain, pengujian, dokumentasi dan pemeliharaan. Secara lengkap metode dalam penelitian ini adalah sebagai berikut :

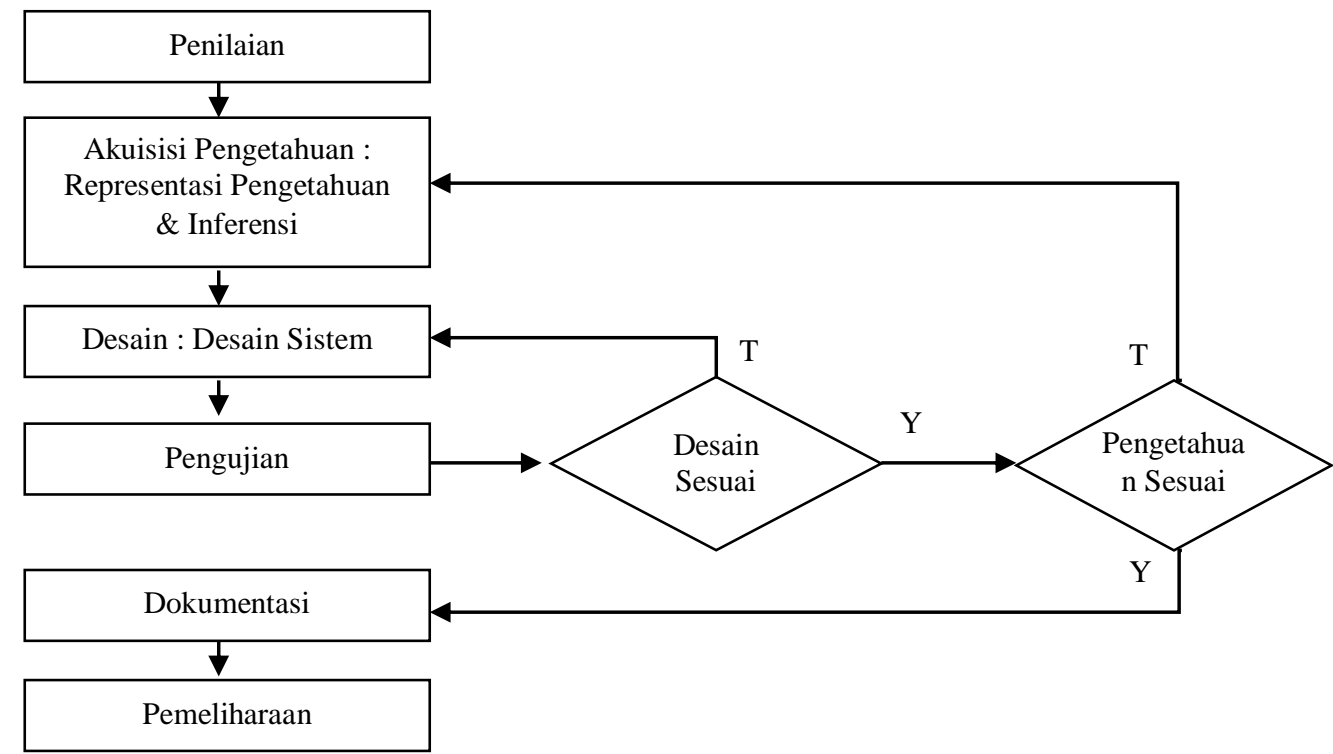

Gambar 2 : Metode Penelitian yang dilakukan

Tahapan penilaian melakukan identifikasi permasalahan, kebutuhan penyelesaian dan penilaian pengetahuan yang mendukung. Proses akuisisi pengetahuan melakukan studi pustaka berkaitan dengan pengetahuan yang mendukung penyelesaian. Pengetahuan studi pustaka kemudian direpresentasikan menggunakan Decission Table dan Decisson Tree dengan menggunakan penalaran inferensi forward chaining. Desain sistem dilakukan untuk menggambarkan sistem yang dirancang menggunakan Unified Modeling Language (UML).

\section{HASIL DAN PEMBAHASAN}

Penyakit pada anak dalam penelitian ini terdiri atas 7 jenis penyakit yang sering terjadi. Basis pengetahuan berisi gejala dari jenis penyakitnya. Berikut basis pengetahuan penyakit pada anak

Tabel 1 : Tabel Penyakit

\begin{tabular}{|c|l|}
\hline $\begin{array}{c}\text { Kode } \\
\text { Penyakit }\end{array}$ & \\
\hline P01 & DBD (Demam Berdarah Dengue) \\
\hline P02 & Demam Tifoid \\
\hline P03 & Campak \\
\hline P04 & Diare \\
\hline P05 & Tetanus \\
\hline P06 & Malaria \\
\hline P07 & Varisela (Cacar Air) \\
\hline
\end{tabular}

Tabel 2 : Tabel Gejala

\begin{tabular}{|c|l|}
\hline Kode Gejala & \\
\hline G01 & Demam \\
\hline G02 & Lesu \\
\hline G03 & Mamas makan \\
\hline G04 & Muntah berak \\
\hline G05 & Pendarahan pada kulit \\
\hline G06 & Mimisan \\
\hline G07 & Sakit Kepala \\
\hline G08 & Tubuh menggigil \\
\hline
\end{tabular}




\begin{tabular}{|l|l|}
\hline G09 & Denyut jantung lemah \\
\hline G10 & Badan lemah \\
\hline G11 & Nyeri otot myalgia \\
\hline G12 & Tidak nafsu makan \\
\hline G13 & Konstipasi \\
\hline G14 & Sakit perut \\
\hline G15 & Penyebaran vlek merah muda \\
\hline G16 & Nyeri tenggorokan \\
\hline G17 & Hidung meler \\
\hline G18 & Batuk \\
\hline G19 & Bercak Koplik \\
\hline G20 & Nyeri otot \\
\hline G21 & Mata merah \\
\hline G22 & Buang air besar terus menerus \\
\hline G23 & Mual \\
\hline G24 & Muntah-muntah \\
\hline G25 & Pegal pada punggung \\
\hline G26 & Perut sering berbunyi \\
\hline G27 & Kekakuan rahang \\
\hline G28 & Nyeri telan \\
\hline G29 & Kejang otot \\
\hline G30 & Sakit Otot \\
\hline G31 & Nyeri perut \\
\hline G32 & Nyeri punggung \\
\hline G33 & Tonjolan-tonjolan kemerahan \\
\hline
\end{tabular}

Tabel 3 : Tabel Relasi Gejala dan Jenis Penyakit

\begin{tabular}{|c|c|c|c|c|c|c|c|}
\hline \multirow[t]{2}{*}{ Kode Gejala } & \multicolumn{7}{|c|}{ PENYAKIT } \\
\hline & P01 & P02 & P03 & P04 & P05 & P06 & P07 \\
\hline G01 & $\sqrt{ }$ & $\sqrt{ }$ & $\sqrt{ }$ & & & $\sqrt{ }$ & $\sqrt{ }$ \\
\hline G02 & $\sqrt{ }$ & & & & & $\sqrt{ }$ & \\
\hline G03 & $\sqrt{ }$ & & & & & & \\
\hline G04 & $\sqrt{ }$ & & & & & & \\
\hline G05 & $\sqrt{ }$ & & & & & & \\
\hline G06 & $\sqrt{ }$ & & & & & & \\
\hline G07 & $\sqrt{ }$ & $\sqrt{ }$ & & & $\sqrt{ }$ & $\sqrt{ }$ & $\sqrt{ }$ \\
\hline G08 & & $\sqrt{ }$ & & & $\sqrt{ }$ & $\sqrt{ }$ & \\
\hline G09 & & $\sqrt{ }$ & & & & & \\
\hline G10 & & $\sqrt{ }$ & & & & & \\
\hline G11 & & $\sqrt{ }$ & & & & & \\
\hline G12 & & $\sqrt{ }$ & & & & $\sqrt{ }$ & \\
\hline G13 & & $\sqrt{ }$ & & & & & \\
\hline G14 & & $\sqrt{ }$ & & & & & \\
\hline G15 & & $\sqrt{ }$ & & & & & \\
\hline G16 & & & $\sqrt{ }$ & & $\sqrt{ }$ & & \\
\hline G17 & & & $\sqrt{ }$ & & & & \\
\hline G18 & & & $\sqrt{ }$ & & & & \\
\hline G19 & & & $\sqrt{ }$ & & & & \\
\hline G20 & & & $\sqrt{ }$ & & & & \\
\hline G21 & & & $\sqrt{ }$ & & & & \\
\hline G22 & & & & $\sqrt{ }$ & & & \\
\hline G23 & & & & $\sqrt{ }$ & & & $\sqrt{ }$ \\
\hline G24 & & & & $\sqrt{ }$ & & & \\
\hline G25 & & & & $\sqrt{ }$ & & & \\
\hline G26 & & & & $\sqrt{ }$ & & & \\
\hline G27 & & & & & $\sqrt{ }$ & & \\
\hline G28 & & & & & $\sqrt{ }$ & & \\
\hline G29 & & & & & $\sqrt{ }$ & & \\
\hline G30 & & & & & & $\sqrt{ }$ & \\
\hline
\end{tabular}




\begin{tabular}{|c|l|l|l|l|l|l|l|}
\hline G31 & & & & & & $\sqrt{ }$ & \\
\hline G32 & & & & & & $\sqrt{ }$ & $\sqrt{ }$ \\
\hline G33 & & & & & & & $\sqrt{ }$ \\
\hline
\end{tabular}

Sesuai dengan pengetahuan dalam tabel diatas, kemudian disusun representasi pengetahuan menggunakan tree. Tree berawal dari pertanyaan fakta yang diajukan kepada pengguna dengan kondisi jawaban "Ya" dan "Tidak". Kondisi pencabangan adalah untuk 2 kondisi "Ya" dan "Tidak", sedangkan kondisi "Ya" tergambar garis tidak bercabang. Kondisi tidak terdeteksi sebagai penyakit pada anak tidak digambarkan dalam tree. Jenis penyakit yang menjadi kesimpulan (goal) berdasarkan fakta yang terjadi merujuk pada inferensi forward chaining.

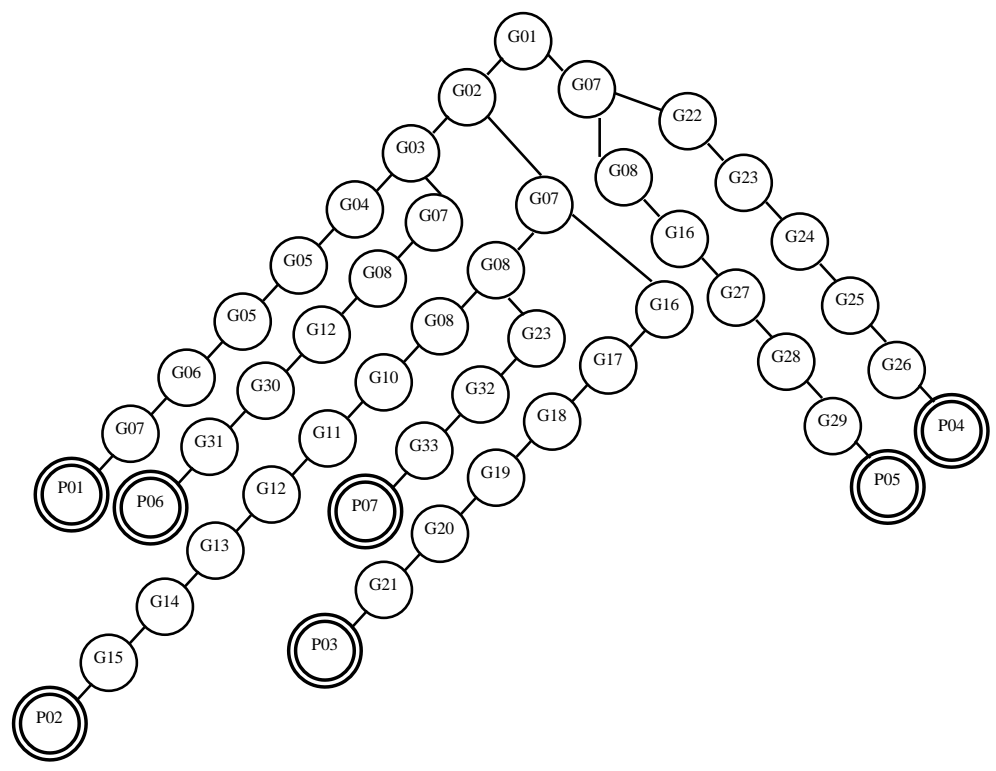

Gambar 3 : Representasi Tree

Skema inferensi forward chaining dimulai dari fakta gejala yang dirasakan oleh pengguna. Gejala pada satu penyakit dapat pula menjadi gejala bagi penyakit lainnya. Gejala dan penyakit tersebut kemudian direlasikan menjadi aturan (rule) seperti contoh rule berikut :

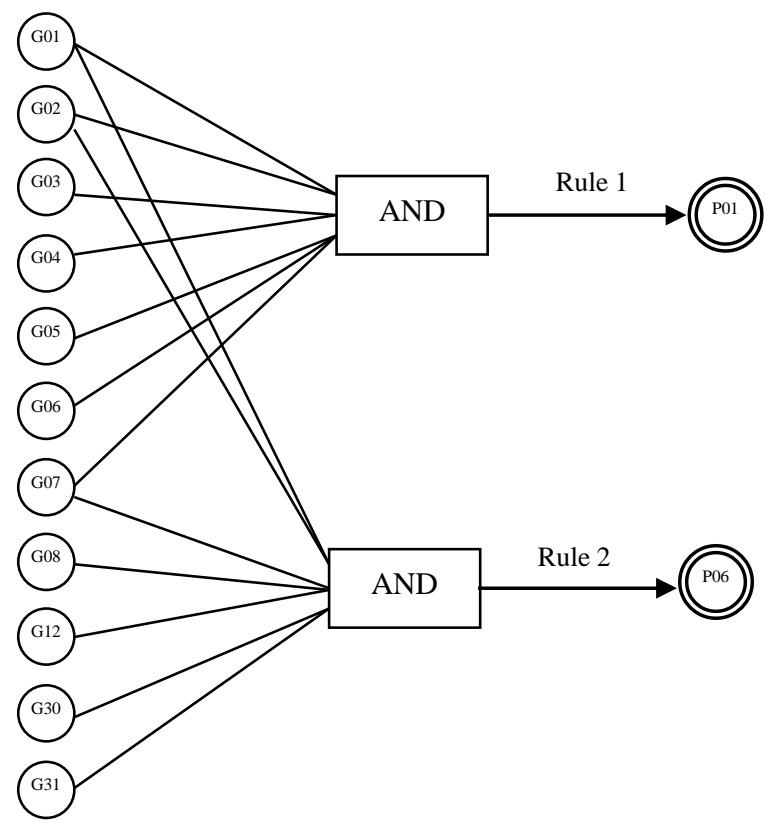

Gambar 4 : Inferensi forward chaining 
Aktor yang berperan dalam sistem adalah pengguna dan pakar. Pakar adalah admin sistem yang membantu seorang pakar dalam memasukkan data pengetahuan kepakaran. Sistem pakar terdiri atas fungsi untuk memasukkan konsultasi gejala. Berdasarkan gejala yang diinputkan kemudian dilakukan proses inferensi untuk menentukan kesimpulan penyakit.

Pengguna melakukan konsultasi melalui user interface sistem pakar dengan memilih gejala yang dirasakan. Sistem akan menampilkan jenis penyakit dan penjelasan atas kesimpulan tersebut. Pengguna dapat mencetak hasil konsulnya dengan terhubung dengan media pencetakan. Aktor pakar melakukan update pengetahuan untuk memastikan bahwa pengetahun pada sistem selalu sesuai dengan perkembangan pengetahuan.

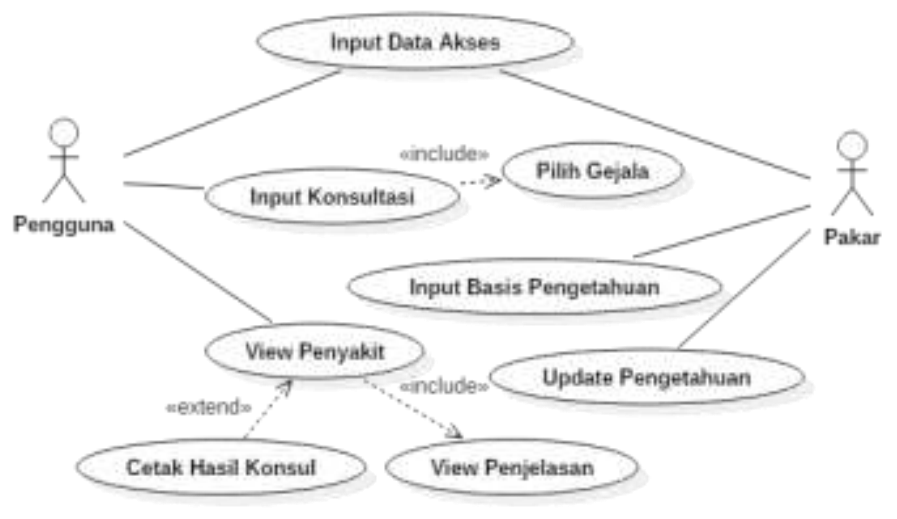

Gambar 5 : Use case Diagram Sistem

\section{KESIMPULAN}

Sistem pakar diagnosis penyakit pada anak dirancang berdasarkan basis pengetahuan mengenai 7 jenis penyakit yang sering terjadi pada anak. Konsultasi dilakukan melalui user interface aplikasi sistem pakar dengan memilih gejala yang dirasakan. Teknik penalaran inferensi melakukan proses pengambilan kesimpulan berdasarkan fakta-fakta yang telah diinputkan untuk kemudian diputuskan jenis penyakitnya.

Penentuan penyakit menggunakan aplikasi sistem pakar selanjutnya dapat dikembangkan pada basis antarmuka yang mudah diakses oleh pengguna serta jenis penyakit yang lebih lengkap terjadi pada anak.

\section{DAFTAR PUSTAKA}

Arhami, Muhammad., 2005, Konsep Dasar Sistem Pakar, Andi Offset, Yogyakarta

David, 2014, Penerapan Forward Chaining Dalam Sistem Pakar Diagnosa Hama Dan Penyakit Tanaman Jagung, Seminar Nasional Informatika, STMIK Pontianak, pp. 90 - 95

Durkin, J. 1994. Expert System: Design and Development. Prentice-Hall Int. Inc., New Jersey. Giarratano, J. \& Riley, G. 2005. Expert System: Principles and Programming, 4th Edition. PWS Publishing Company, Boston.

Helen Sastypratiwi \& Fatma Agus Setyaningsih, 2014, Aplikasi untuk Diagnosis Penyakit pada Anak dan Balita Menggunakan Faktor Kepastian, Seminar Nasional Informatika Medis (SNIMed) V, pp. $82-92$

Kusumadewi, Sri., 2003, Artificial Intelligence (Teknik dan Aplikasinya), Graha Ilmu, Yogyakarta.

Luther A. Latumakulita, 2012, Sistem Pakar Pendiagnosa Penyakit Anak Menggunakan Certainty Factor (CF), Jurnal Ilmiah Sains Vol. 12 No. 2, pp. 121 - 126 